\title{
13th European Headache Federation Congress 2019: Meeting Abstracts - part 2
}

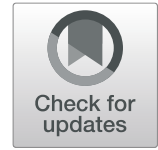

Athens, Greece. May 30-June 12,2019

Published: 12 May 2020

A.56

Efficacy of fremanezumab in patients with migraine and documented inadequate response to 2,3 , or 4 classes of migraine preventive treatments: results of the international, multicenter, randomised, placebo-controlled FOCUS study

Ladislav Pazdera', Xiaoping Ning ${ }^{2}$, Maja Galic ${ }^{3}$, Joshua M. Cohen², Ronghua Yang ${ }^{2}$

${ }^{1}$ Vestra clinics, Rychnov nad Kněžnou, Czech Republic; ${ }^{2}$ Teva pharmaceuticals industries, Frazer, PA, USA; ${ }^{3}$ Teva pharmaceuticals, Amsterdam, the Netherlands

The Journal of Headache and Pain 2020, 21(Suppl 1):A.56

Background: Fremanezumab, a fully-humanised monoclonal antibody $(\operatorname{lgG} 2 \Delta \mathrm{a})$ that selectively targets calcitonin gene-related peptide (CGRP), has proven efficacy for migraine preventive treatment in adults. The FOCUS study of fremanezumab was the first and largest study of a migraine preventive treatment in adults with both chronic and episodic migraine (CM and EM) and documented inadequate response to 2-4 classes of migraine preventive medications.

Methods: For 12 weeks of double-blind treatment, patients were randomised (1:1:1) to monthly fremanezumab (Month 1: CM, 675 mg; EM, $225 \mathrm{mg}$; Months 2 and 3: $225 \mathrm{mg}$ ), quarterly fremanezumab (Month 1: $675 \mathrm{mg}$; Months 2 and 3: placebo), or matched monthly placebo. Changes from baseline in monthly average migraine days and response rates $(\geq 50 \%$ reduction in mean monthly number of migraine days for 12 weeks) were evaluated by number of classes of migraine preventive treatments to which patients showed inadequate response.

Results: Of 838 randomized patients, 50\%, 32\%, and $18 \%$ had inadequate response to 2,3 , and 4 preventive medication classes, respectively. Changes from baseline in monthly average migraine days over 12 weeks were significantly greater with monthly and quarterly fremanezumab, respectively, vs placebo among patients with inadequate response to 2 (LSMD vs placebo: $-3.7,-2.9), 3$ $(-2.9,-3.3)$, or $4(-5.4,-5.3)$ medication classes (all $P<0.0001$ ). Proportions of patients who achieved $\geq 50 \%$ reductions in migraine days at 12 weeks were significantly greater with monthly and quarterly fremanezumab, respectively, vs placebo among patients with inadequate response to 2 ( $41 \%$ and $39 \%$ vs $11 \%$ ), 3 ( $28 \%$ and $32 \%$ vs $7 \%)$, or $4(32 \%$ and $27 \%$ vs $4 \%)$ classes (all $P \leq 0.002)$
Discussion: For migraine patients with documented inadequate response to 2,3 , or 4 classes of migraine preventive medications, reductions in monthly average migraine days and clinically meaningful response rates were significantly greater with fremanezumab vs placebo.

\section{A.57 \\ Impact of age and sex on efficacy of fremanezumab in patients with migraine and documented inadequate response to 2-4 classes of migraine preventive treatments: results of the international, multicentre, randomised, placebo-controlled FOCUS study Antoinette MaassenVanDenBrink', Maja Galic ${ }^{2}$, Joshua M. Cohen ${ }^{3}$, Xiaoping Ning ${ }^{3}$, Ronghua Yang $^{3}$, Verena Ramirez-Campos ${ }^{3}$ ${ }^{1}$ Department of internal medicine, division of vascular medicine and pharmacology, Erasmus MC, Rotterdam, the Netherlands; ${ }^{2}$ Teva pharmaceuticals, Amsterdam, the Netherlands; ${ }^{3}$ Teva pharmaceuticals industries, Frazer, PA, USA \\ The Journal of Headache and Pain 2020, 21(Suppl 1):A.57}

Correspondence: Joshua M. Cohen

Background: The FOCUS study of fremanezumab, a fully-humanised monoclonal antibody (lgG2 $\triangle \mathrm{a})$ that selectively targets calcitonin gene-related peptide (CGRP), was the first and largest study of a migraine preventive treatment in adults with both episodic and chronic migraine (EM and CM) and documented inadequate response to 2-4 classes of preventive treatments.

Methods: Patients were randomised (1:1:1) to monthly fremanezumab (Month 1: EM, $225 \mathrm{mg}$; CM, $675 \mathrm{mg}$; Months 2 and 3: $225 \mathrm{mg}$ ), quarterly fremanezumab (Month 1: $675 \mathrm{mg}$; Months 2 and 3: placebo), or matched monthly placebo for 12 weeks of double-blind treatment. Changes from baseline in monthly average number of migraine days over 12 weeks were evaluated by sex and age.

Results: 838 patients were randomised. Reductions in monthly average migraine days were significantly greater with both fremanezumab dosing regimens vs placebo in subgroups of males, females, and ages $18-45$ and $>45$ years (all $P<0.0001 ;$ Table).

Discussion: Fremanezumab was efficacious, based on statistically significant reductions in monthly average migraine days vs placebo, in males, females, and those aged $\leq 45$ and $>45$ years with inadequate response to 2-4 classes of migraine preventive treatments.

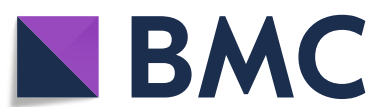

(c) The Author(s). 2020 Open Access This article is licensed under a Creative Commons Attribution 4.0 International License, which permits use, sharing, adaptation, distribution and reproduction in any medium or format, as long as you give appropriate credit to the original author(s) and the source, provide a link to the Creative Commons licence, and indicate if changes were made. The images or other third party material in this article are included in the article's Creative Commons licence, unless indicated otherwise in a credit line to the material. If material is not included in the article's Creative Commons licence and your intended use is not permitted by statutory regulation or exceeds the permitted use, you will need to obtain permission directly from the copyright holder. To view a copy of this licence, visit http://creativecommons.org/licenses/by/4.0/ The Creative Commons Public Domain Dedication waiver (http://creativecommons.org/publicdomain/zero/1.0/) applies to the data made available in this article, unless otherwise stated in a credit line to the data. 
Table 1 (abstract A.57). Change from baseline in monthly average migraine days during 12-weeks of double-blind treatment by sex and age group ${ }^{\mathrm{a}}$

\begin{tabular}{|c|c|c|c|}
\hline & Placebo & $\begin{array}{l}\text { Monthly } \\
\text { fremanezumab }\end{array}$ & $\begin{array}{l}\text { Quarterly } \\
\text { fremanezumab }\end{array}$ \\
\hline Males & $(n=46)$ & $(n=45)$ & $(n=47)$ \\
\hline LSM (SE) change & $\begin{array}{l}-0.4 \\
(0.74)\end{array}$ & $-4.6(0.78)$ & $-4.2(0.73)$ \\
\hline $\begin{array}{l}\text { LSMD (SE) vs } \\
\text { placebo }\end{array}$ & - & $-4.2(0.91)^{\mathrm{b}}$ & $-3.8(0.87)^{\mathrm{b}}$ \\
\hline Females & $(n=232)$ & $(n=238)$ & $(n=229)$ \\
\hline LSM (SE) change & $\begin{array}{l}-0.6 \\
(0.35)\end{array}$ & $-3.9(0.34)$ & $-3.6(0.35)$ \\
\hline $\begin{array}{l}\text { LSMD (SE) vs } \\
\text { placebo }\end{array}$ & - & $-3.3(0.39)^{b}$ & $-3.0(0.39)^{\mathrm{b}}$ \\
\hline Age $18-45$ years & $(n=120)$ & $(n=128)$ & $(n=125)$ \\
\hline LSM (SE) change & $\begin{array}{l}-0.8 \\
(0.47)\end{array}$ & $-4.6(0.49)$ & $-4.1(0.48)$ \\
\hline $\begin{array}{l}\text { LSMD (SE) vs } \\
\text { placebo }\end{array}$ & - & $-3.8(0.51)^{\mathrm{b}}$ & $-3.2(0.51)^{b}$ \\
\hline Age $>45$ years & $(n=158)$ & $(n=155)$ & $(n=151)$ \\
\hline LSM (SE) change & $\begin{array}{l}-0.4 \\
(0.48)\end{array}$ & $-3.8(0.47)$ & $-3.6(0.49)$ \\
\hline $\begin{array}{l}\text { LSMD (SE) vs } \\
\text { placebo }\end{array}$ & - & $-3.4(0.50)^{b}$ & $-3.2(0.51)^{b}$ \\
\hline
\end{tabular}

LSM least-squares mean, $L S M D$ LSM difference

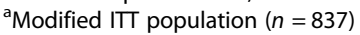

${ }^{\mathrm{b}} P<0.0001$ vs placebo

\section{A.58}

Early onset of response to fremanezumab in patients with migraine and a documented inadequate response to 2-4 classes of migraine preventive treatments: results of the international, multicentre, randomised, placebo-controlled FOCUS study

Egilius L.H. Spierings ${ }^{1}$, Martina Machkova ${ }^{2}$, Xiaoping Ning ${ }^{3}$, Maja Galic ${ }^{4}$, Joshua M. Cohen ${ }^{3}$, Ronghua Yang ${ }^{3}$

${ }^{1}$ Medvadis Research Corporation, Watertown, MA, USA; ${ }^{2}$ CCR Czech

Prague, Prague, Czech Republic; ${ }^{3}$ Teva pharmaceuticals industries, Frazer, PA, USA; ${ }^{4}$ Teva pharmaceuticals, Amsterdam, the Netherlands

The Journal of Headache and Pain 2020, 21(Suppl 1):A.58

\section{Correspondence: Joshua M. Cohen}

Background: Preventive treatments for episodic and chronic migraine (EM and CM) have been associated with slow onset of action. Fremanezumab, a fully-humanised monoclonal antibody (lgG2 $\Delta$ a) that selectively targets calcitonin gene-related peptide (CGRP), has proven efficacy for preventive migraine treatment in adults. The FOCUS study of fremanezumab was the first and largest study of a migraine preventive treatment in adults with both EM and CM and documented inadequate response to 2-4 classes of migraine preventive treatments.

Methods: Patients were randomised (1:1:1) to monthly fremanezumab (Month 1: EM, $225 \mathrm{mg} ; \mathrm{CM}, 675 \mathrm{mg}$; Months 2 and 3: $225 \mathrm{mg}$ ), quarterly fremanezumab (Month 1: $675 \mathrm{mg}$; Months 2 and 3: placebo), or matched monthly placebo for 12 weeks of double-blind treatment. Proportions of responders ( $\geq 50 \%$ and $\geq 75 \%$ reduction in migraine days) over the first 4 weeks were evaluated as secondary and exploratory endpoints, respectively. Changes from baseline in weekly migraine days were compared using a mixed-effects model for repeated measures.

Results: 838 patients were randomised. With monthly and quarterly fremanezumab, respectively, vs placebo, significantly higher proportions of patients achieved $\geq 50 \%$ reductions ( $36 \%$ and $38 \%$ vs $10 \%$ ) and $\geq 75 \%$ reductions $(14 \%$ and $14 \%$ vs $2 \%$ ) in migraine days over the first 4 weeks (all $P<0.0001$ ). Reductions from baseline in weekly migraine days were significantly greater with fremanezumab (LSM[SE] change: monthly, $0.9[0.11]$; quarterly, $-1.0[0.11])$ vs placebo $(-0.1[0.11])$ by Week 1 and at each weekly time point through Week 4 (all $P<0.0001$ ).
Discussion: Monthly and quarterly fremanezumab demonstrated early onset of efficacy, with significantly greater clinically meaningful response rates after 4 weeks of treatment and significantly greater reductions from baseline in weekly migraine days as early as Week 1 vs placebo, in patients with EM or CM and documented inadequate response to 2-4 classes of migraine preventive treatments.

\section{A.59}

Efficacy, clinically meaningful responses, and impact on acute headache medication use with fremanezumab in patients with migraine and documented inadequate response to 2-4 classes of migraine preventive treatments: results of the international, multicentre, randomised, placebo-controlled FOCUS study Michel D. Ferrari ${ }^{1}$, Hans Christoph Diener ${ }^{2}$, Egilius L.H. Spierings ${ }^{3}$, Xiaoping Ning ${ }^{4}$, Maja Galic ${ }^{5}$, Joshua M. Cohen ${ }^{4}$, Ronghua Yang ${ }^{4}$, Messoud Ashina ${ }^{6}$

${ }^{1}$ Leiden University Medical Centre (LUMC), Leiden, The Netherlands;

${ }^{2}$ Faculty of Medicine, University of Duisburg-Essen, Essen, Germany;

${ }^{3}$ Medvadis Research Corporation, Watertown, MA, USA; ${ }^{4}$ Teva

Pharmaceuticals Industries, Frazer, PA, USA; ${ }^{5}$ Teva Pharmaceuticals,

Amsterdam, The Netherlands; ${ }^{6}$ Danish headache Centre, Department of Neurology, Rigshospitalet, Glostrup, Denmark

The Journal of Headache and Pain 2020, 21(Suppl 1):A.59

Correspondence: Joshua M. Cohen

Background: Fremanezumab, a fully-humanised monoclonal antibody $(\lg G 2 \Delta \mathrm{a})$ that selectively targets calcitonin gene-related peptide (CGRP), has proven efficacy for migraine preventive treatment in adults. The FOCUS study of fremanezumab was the first and largest study of a migraine preventive treatment in adults with both episodic and chronic migraine (EM and CM) and documented inadequate response to 2-4 classes of migraine preventive treatments.

Methods: Patients were randomised (1:1:1) to monthly fremanezumab (Month 1: EM, $225 \mathrm{mg} ; \mathrm{CM}, 675 \mathrm{mg}$; Months 2 and 3: $225 \mathrm{mg}$ ), quarterly fremanezumab (Month 1: $675 \mathrm{mg}$; Months 2 and 3: placebo), or matched monthly placebo for 12 weeks. The primary efficacy endpoint was the change from baseline in monthly average migraine days over 12 weeks. Responder rates $(\geq 50 \%$ and $\geq 75 \%$ reduction in migraine days) and monthly average days of acute headache medication use were also evaluated.

Results: 838 patients were randomised. Reductions from baseline in monthly average migraine days over 12 weeks were greater with fremanezumab (LSM[SE] change: monthly, $-4.1[0.34]$; quarterly, $3.7[0.34])$ vs placebo $(-0.6[0.34]$; both $P<0.0001)$. With monthly and quarterly fremanezumab, respectively, vs placebo, higher proportions of patients achieved $\geq 50 \%$ ( $34 \%$ and $34 \%$ vs $9 \%$ ) and $\geq 75 \%(12 \%$ and $8 \%$ vs $2 \%$ ) reductions in migraine days over 12 weeks (all $P \leq$ 0.0002). Reductions in monthly average days of acute headache medication use were greater with fremanezumab (LSM[SE] change: monthly, $-3.9[0.32]$; quarterly, $-3.7[0.32])$ vs placebo $(-0.6[0.32])$ over 12 weeks, as were reductions in monthly average days of migraine-specific acute headache medication use (all $\mathrm{P}<0.0001$ ).

Discussion: Reductions in monthly average migraine days and days of acute headache medication use and clinically meaningful response rates were significantly greater with fremanezumab vs placebo in migraine patients with documented inadequate response to 2-4 classes of migraine preventive treatments.

\section{A.60}

Efficacy and safety of fremanezumab in patients with migraine and documented inadequate response to 2-4 classes of migraine preventive treatments: results of the international, multicentre, randomised, placebo-controlled FOCUS study

Michel D. Ferrari ${ }^{1}$, Hans Christoph Diener ${ }^{2}$, Xiaoping Ning ${ }^{3}$, Maja Galic ${ }^{4}$, Joshua M. Cohen ${ }^{3}$, Ronghua Yang ${ }^{3}$, Messoud Ashina ${ }^{5}$

'Leiden university medical Centre (LUMC), Leiden, the Netherlands; ${ }^{2}$ University of Duisburg-Essen, Essen, Germany; ${ }^{3}$ Teva pharmaceuticals industries, Frazer, PA, USA; ${ }^{4}$ Teva pharmaceuticals, Amsterdam, the Netherlands; ${ }^{5}$ Danish headache Centre, Department of Neurology, Rigshospitalet, Glostrup, Denmark

The Journal of Headache and Pain 2020, 21(Suppl 1):A.60 
Correspondence: Joshua M. Cohen

Background: Fremanezumab, a fully-humanised monoclonal antibody $(\operatorname{lgG} 2 \Delta \mathrm{a})$ that selectively targets calcitonin gene-related peptide (CGRP), is effective for the preventive treatment of migraine. The FOCUS study of fremanezumab was the first and largest study of a migraine preventive treatment in patients with both episodic and chronic migraine (EM and $\mathrm{CM}$ ) and documented inadequate response to 2-4 classes of migraine preventive treatments.

Methods: For 12 weeks of double-blind treatment, patients were randomised (1:1:1) to monthly fremanezumab (Month 1: EM, $225 \mathrm{mg}$; CM $675 \mathrm{mg}$; Months 2 and 3: $225 \mathrm{mg}$ ), quarterly fremanezumab (Month 1, $675 \mathrm{mg}$; Months 2 and 3, placebo), or matched monthly placebo. The primary efficacy endpoint was mean change from baseline in monthly average migraine days over 12 weeks and was compared using analysis of covariance.

Results: 838 patients were randomised. Reductions from baseline in monthly average migraine days over 12 weeks were significantly greater with monthly fremanezumab (least-squares mean[SE] change, -4.1 [0.34]) and quarterly fremanezumab $(-3.7[0.34])$ versus placebo $(-0.6[0.34]$ both $P<0.0001$ in the overall population. In subgroups of patients with $\mathrm{EM}$ and $\mathrm{CM}$, reductions from baseline in monthly average migraine days were also significantly greater with both fremanezumab regimens versus placebo (all $\mathrm{P}<0.0001$ ). The incidence of AEs was similar in the placebo and combined fremanezumab groups, respectively, including overall $A E S$ $(48 \%$ and $50 \%)$, AEs leading to discontinuation $(1 \%$ and $<1 \%)$, and SAEs $(1 \%$ and $1 \%)$. None of the SAEs were considered treatment-related, and no safety signals were identified.

Discussion: Fremanezumab demonstrated significant improvements in efficacy, based on reductions in monthly average migraine days versus placebo, and was safe and well tolerated over 3 months in patients with $\mathrm{EM}$ or $\mathrm{CM}$ and documented inadequate response to multiple classes of migraine preventive treatments.

\section{Publisher's Note}

Springer Nature remains neutral with regard to jurisdictional claims in published maps and institutional affiliations.
Ready to submit your research? Choose BMC and benefit from:

- fast, convenient online submission

- thorough peer review by experienced researchers in your field

- rapid publication on acceptance

- support for research data, including large and complex data types

- gold Open Access which fosters wider collaboration and increased citations

- maximum visibility for your research: over $100 \mathrm{M}$ website views per year

At $\mathrm{BMC}$, research is always in progress.

Learn more biomedcentral.com/submissions 